\title{
DIRECTIONAL FLOW OF FALLOPIAN TUBE SECRETION IN THE EWE AT ONSET OF THE BREEDING SEASON
}

\author{
A. R. BELLVE AND M. F. MaDONALD \\ Department of Sheep Husbandry, Massey University, \\ Palmerston North, New Zealand \\ (Received 11th November 1969)
}

The secretion of fluid in the Fallopian tube is greatest about oestrus and diminishes during the luteal phase of the cycle (e.g. Perkins, Goode, Wilder \& Henson, 1965). Cannulation of both ends of the Fallopian tube in the ewe and volumetric collection of the secretion has shown that most of the fluid flowed through the ampullar orifice, but that there was marked increase in flow of fluid through the tubo-uterine junction about 4 days after the onset of oestrus (Bellve \& McDonald, 1968). With the ovariectomized ewe injected with oestrogen, the peak flow through the tubo-uterine junction preceded that through the ampullar end (McDonald \& Bellve, 1969). The mechanism which prevents a similar premature surge in isthmic flow in the intact ewe during the pre-ovulatory period, when oestrogen is in dominance (Moore, Barrett, Brown, Schindler, Smith \& Smyth, 1969) is obscure, but progesterone from the corpus luteum of the previous ovulation may have a regulatory rôle. Nevertheless, in the spayed ewe sequentially treated with progesterone and oestrogen, isthmic flow was not effectively restricted relative to ampullar flow (McDonald \& Bellve, 1969).

The transition from the anoestrous season to the breeding season is a convenient time at which to examine the direction of fluid flow in the intact animal when ovulation occurs in the absence of progesterone from a 'waning' corpus luteum.

Six, 5-year-old, Romney ewes were used during March to April 1967, after ensuring at laparotomy that no corpora lutea were initially present in the ovaries. Vaginal smears were taken daily, stained and assessed by the method of Robinson \& Moore (1956) for evidence of ovarian activity. Insertion of cannulae into the ovarian (ampullar) and uterine (isthmic) ends of a Fallopian tube in each ewe and daily collection of tubal fluid was as described by Bellve \& McDonald (1968). Fluid was collected until the approach of the third ovulatory period (second oestrus) of the breeding season, when each ewe was slaughtered and the ovaries recovered. Each set of ovaries showed two distinct generations of corpora lutea and their morphological appearance indicated that they were the result of ovulations as judged by the changes seen in vaginal smears and the fluctuations in output of tubal fluid.

The first ovulation in the breeding season is usually unaccompanied by 
oestrous behaviour (in contrast to ovulation of the second ovarian cycle), and as cellular and mucous changes in vaginal smears were not satisfactory for determining the exact day of ovulation (Robinson \& Moore, 1956), the first day of marked increase in tubal secretion was taken as Day 1 of each ovarian cycle.

Text-figure 1 shows the mean daily fluid secretion, ampullar flow and isthmic flow of five ewes which completed two ovarian cycles (data from the remaining ewe were excluded owing to failure of a cannula). Analyses of variance of these data are given in Table 1.

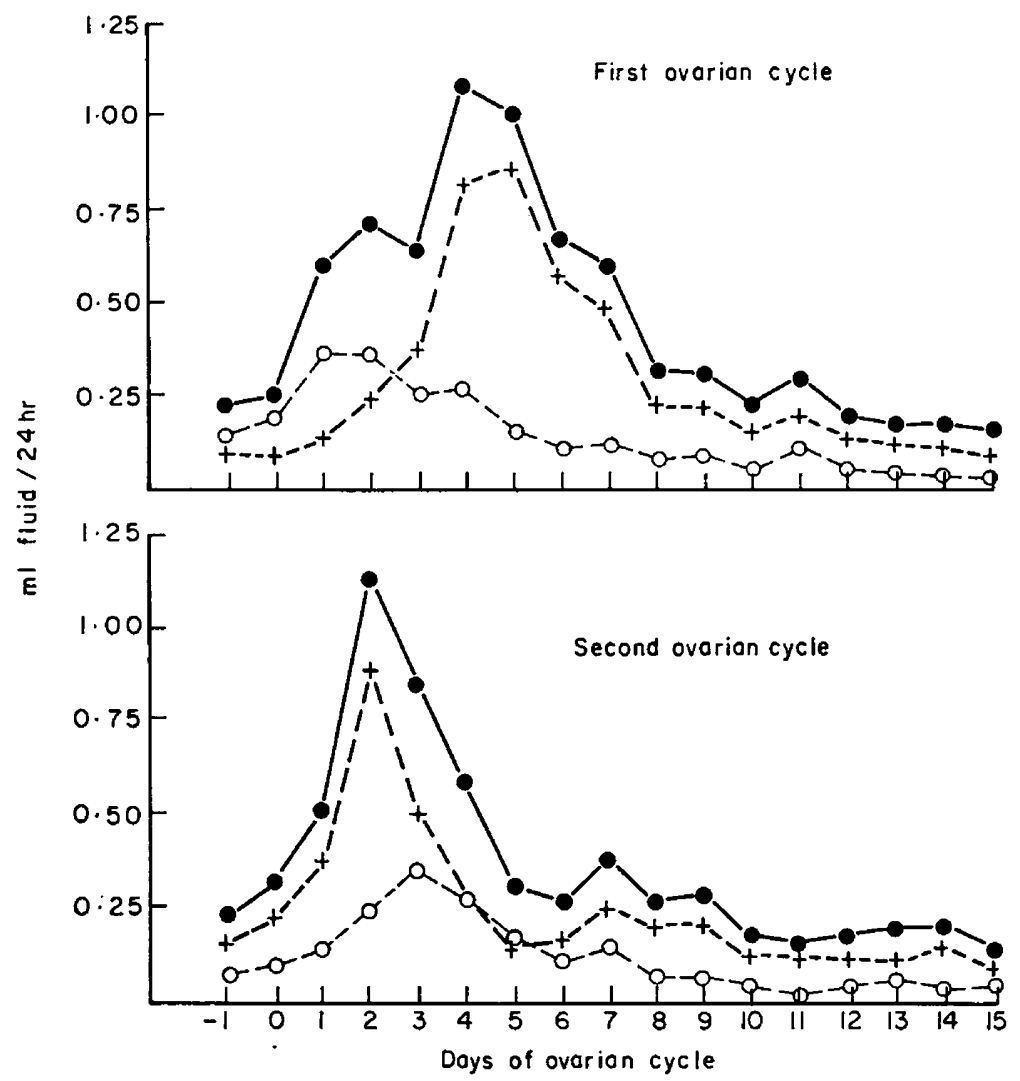

Text-Fig. 1. Mean daily secretion of tubal fluid (e), and flow through the ovarian (ampullar, +) and uterine (isthmic, $O$ ) ends of Fallopian tubes in ewes at first and second ovarian cycles of the breeding season.

The major point of interest is that the pattern of fluid flow differed markedly between the two ovarian cycles. In respect of ampullar flow, there was a significant $(P<0.01)$ ovarian cycle $\times$ day interaction and this is readily apparent as a difference in the order of day means about Day 4 . While an interaction term is not evident in the data for isthmic flow, significant $(P<0.01)$ differences in flow existed between days of both ovarian cycles. The overall effect was that, in the first ovarian cycle, peak isthmic flow preceded the peak ampullar flow by $1.7 \pm 0.9$ days; in the second ovarian cycle, peak isthmic flow followed that of 
ampullar flow by $1.1 \pm 0.5$ days. Thus, the sequence of flow in the first ovarian cycle was the same as in the oestrogen-treated, ovariectomized animal. By contrast, the sequence of fluid flow in the next ovarian cycle was similar to that recorded during the normal oestrous cycle (Bellve \& McDonald, 1968).

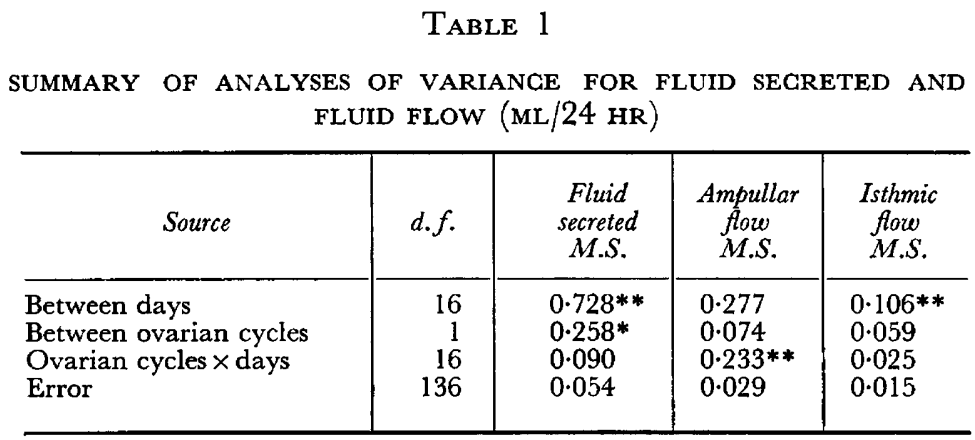

M.S. $=$ Mean square. ${ }^{*} P<0.05 ; * * P<0 \cdot 01$.

In assessing these results, it should be noted that the flow of tubal fluid, although initially variable, had reached equilibrium levels before the marked increase which occurred about the time of first ovulation. Furthermore, the pattern of ampullar and isthmic flow recorded in the first ovarian cycle is not necessarily characteristic for ewes during the first ovarian cycle following cannulation, e.g. cyclic ewes subjected to cannulation during the breeding season have shown a different pattern of flow (Bellve \& McDonald, 1968). Thus, the present results would seem to indicate that the corpus luteum, presumably by means of progesterone, can prevent the increase in isthmic flow during the period of oestrogen dominance before the next ovulation.

\section{REFERENCES}

Bellve, A. R. \& MaDonald, M. F. (1968) Directional flow of Fallopian tube secretion in the Romney ewe. F. Reprod. Fert. 15, 357.

MaDonald, M. F. \& Bellve, A. R. (1969) The influence of oestrogen and progesterone on flow of fluid from the Fallopian tube in the ovariectomized ewe. F. Reprod. Fert. $20,51$.

Moore, N. W., Barrett, S., Brown, J. B., Schindler, I., Smith, M. A. \& Smyth, B. (1969) Oestrogen and progesterone content of ovarian vein blood of the ewe during the oestrous cycle. F. Endocr. 44, 55 .

Perkins, J. L., Goode, L., Wilder, W. A. \& Henson, D. B. (1965) Collection of secretions from the oviduct and uterus of the ewe. F. Anim. Sci. 24, 383.

Robinson, T. J. \& Moore, N. M. (1956) The interaction of oestrogen and progesterone on the vaginal cycle of the ewe. F. Endocr. 14, 97. 